\section{NUMERICAL MODELLING OF OSCILLATING FLOW FOR ENERGY HARVESTING} TOMAS BLEJCHAR ${ }^{1}$, SYLVA DRABKOVA ${ }^{1}$, VACLAV JANUS ${ }^{2}$

${ }^{1}$ Faculty of Mechanical Engineering

${ }^{2}$ Faculty of Electrical Engineering and Informatics

VSB - Technical University of Ostrava, Czech Republic

DOI: 10.17973/MMSJ.2021_12_2021102

e-mail: tomas.blejchar@vsb.cz

The energy efficiency of systems, equipment, and sensors is nowadays intensively studied. The new generation of microelectronic sensors is very sophisticated and the energy consumption is in the microwatts range. The energy to power the microelectronic devices can be harvested from oscillating flow in small size channels and so replaceable batteries could be eliminated. Piezoelectric elements can convert energy from oscillation to electrical energy. This paper focuses on the simulation of periodic flow in the fluidic oscillator. CFD simulations were performed for several values of the flow rate. Experimental measurement was carried out under the same conditions as the CFD experiment. The main monitored and evaluated parameters were volume flow rate and pressure loss. Fluid oscillations were analysed based on CFD simulations and the theoretical maximum energy available for the deformation of piezoelectric elements and transformable into electrical energy was evaluated.

KEYWORDS

Energy harvesting; oscillating flow; fluidic oscillator; computational fluid dynamics (CFD); experimental measurement

\section{INTRODUCTION}

Fluidic oscillators are relatively simple devices with generally no moving parts. Their design goes back to the $60 \mathrm{~s}$ and $70 \mathrm{~s}$ when the first fluidic flow meters were invented and patented [Warren 1960] and applied [Tippets at al. 1973]. Since that time, the range of their application has increased significantly. They are used as actuators for the flow control [Gregory et al. 2013], [Woszidlo et al. 2019], in combustion control [Guyot et al. 2008], boundary layer modification in turbomachinery [Cerretelli et al. 2009], flow separation control on aerofoils [Tesař et al. 2013], noise reduction in cavities [Raman and Raghu 2012] and many other fields. The growing interest in their application has brought the need for a better understanding of the internal flow patterns and the oscillation mechanism. The first analyses were carried out experimentally, e.g. [Bobusch et al. 2013], [Ostermann et al. 2015]. Later on, numerical investigations of fluidic oscillators were performed to understand the unsteady internal flow field and geometrical effects on its performance [Krüger et al. 2013], [Pandey and Kim 2018].

There are two types of fluidic flowmeters working on different principles. The first works on momentum exchange in double feedback designs, the second is mainly governed by the physical phenomenon known as the Coanda effect, which attaches fluid stream alternatively to one of the adjacent walls in the mixing chamber. The geometric shape of the Coanda flowmeters generates a continuous, self-induced oscillation. Due to this switching characteristic, they are considered pressure driven devices [Baghaei and Bergada 2019].
In recent years, sensing, monitoring, and control have become topical problem in the industry as well as in our daily life. Owing to the fact that the size and energy consumption of electronic devices decreases, there has been a growing interest in harvesting these small amounts of energy from the environment and developing self-powered devices. Fluid dynamics has the potential to be one of such small energy sources. [Hamlehdar et al. 2019] presented a critical review of the energy harvesting techniques from fluid flow using piezoelectric materials. Fluidic oscillators can generate small periodic forces acting on the elastic structure of piezoelectric elements.

The objective of this paper was to investigate the performance of the Coanda fluidic oscillator presented in the recent study [McDonough et al. 2017]. The authors focused on experimental analyzing the effects of varying fluidic oscillator geometries on the flow-switching frequencies as well as the effect of working liquid physical properties. The outcomes of their work inspired us to carry out a numerical analysis. The current paper presents a numerical evaluation of the same fluidic oscillator configuration presented in [McDonough et al. 2017]. The basic fluidic geometry operated with water was tested numerically via a 3D -computational fluid dynamics (CFD). The performance was evaluated at low Reynolds numbers and compared with the experimental measurement.

\section{FLUIDIC OSCILLATOR MODEL}

\subsection{Basic configuration and geometry}

Fig. 1 shows the basic design of the fluidic oscillator [McDonough et al. 2017].

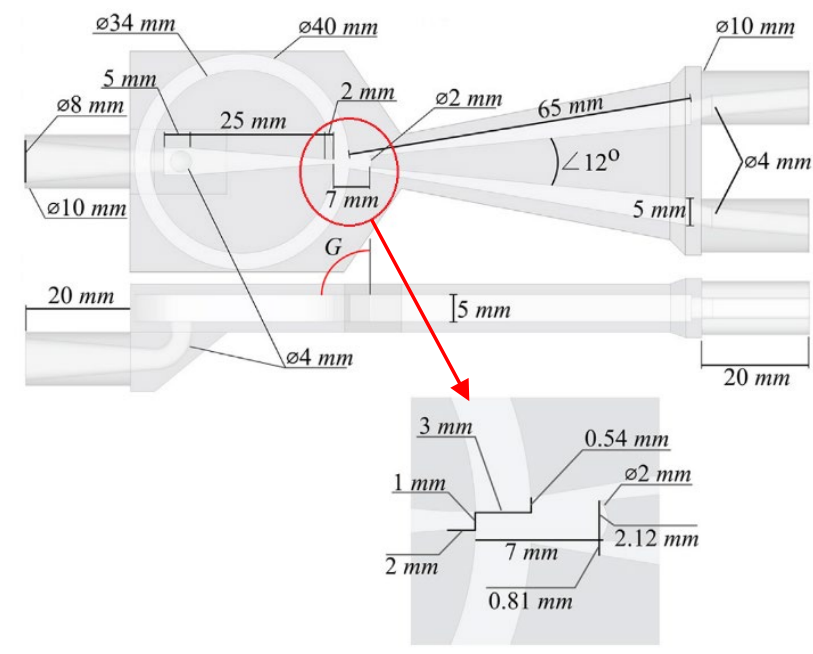

Figure 1. Basic fluidic oscillator dimensions

The single feedback loop design includes a supply port, two outlet channels, and two control ports that are connected through a single feedback loop. The main geometrical parameters define a $1 \mathrm{~mm}$ nozzle constriction size and $25 \mathrm{~mm}$ nozzle convergence length, with a total inlet distance of $32 \mathrm{~mm}$. A splitter with $1 \mathrm{~mm}$ diameter con-cave wall is positioned after the nozzle at a distance of $7 \mathrm{~mm}$. Also located adjacent to the nozzle are two control ports, connected by a $3 \mathrm{~mm}$ wide and 101 $\mathrm{mm}$ long feedback loop. Due to the position of the feedback loop, the liquid is supplied via a 90 obend, converging from an 8 $\mathrm{mm}$ to $4 \mathrm{~mm}$ tube diameter. The two outlet channels are $65 \mathrm{~mm}$ long and the diameters of the outlet ports are $4 \mathrm{~mm}$ [McDonough et al. 2017].

A Fluid jet emerging from a nozzle bends toward and attaches itself to an adjacent surface. A low-pressure vortex forms between the attachment wall and the attached jet. A portion of 
the flow with higher pressure passes through a feedback loop and travels back to the control port. This feedback flow breaks the jet attachment and pushes it toward the opposite sidewall. The frequency of switching is proportional to the volume flow rate.

\subsection{D printing of the fluidic oscillator prototype}

Design for 3D print was made in Fusion360 CAD software. The template dimensions were followed through with the exception of the inlet and the outlet sections. The pressure chambers, where the sensors were placed, are just oriented on a vertical axis. This change would not lead to any major differences in the flow. First prints (Fig.2) were designed with a cover made of acrylic glass, that was screwed in place. Sealing was done using rubber filament and a series of grooves to prevent any leakage under the lid. Unfortunately, this never worked and was used only to test how would the printed material hold out against the current.

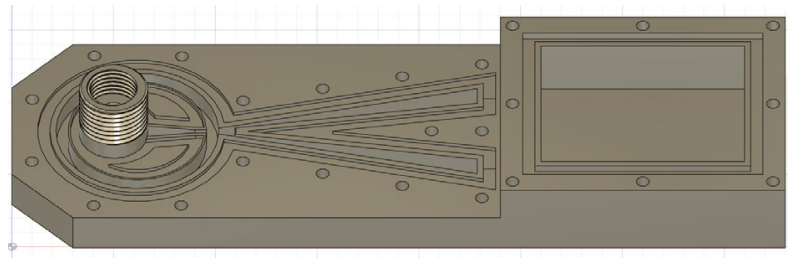

Figure 2. Fluidic version with the lid

Follow-up versions were printed as a whole (Fig. 3). The inlet and outlet parts were modeled for use with $\mathrm{G} 1 / 4$ inch brass couplings. With Teflon tape as a sealer, no leakage was observed. The whole body of the fluidic was made with PLA and PET-G on a Prusa mk3 printer. After observing that PLA was holding strong, tests were made on the fluidic made with PLA.

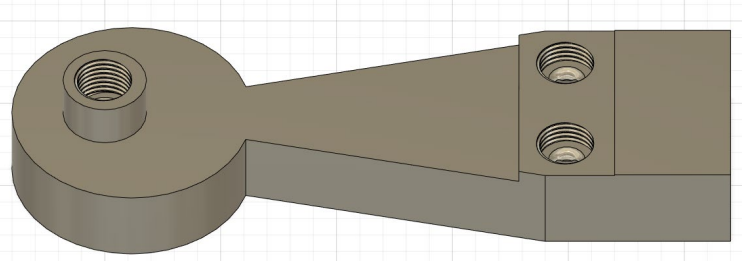

Figure 3. Fluidic version printed as whole

Sensors used the same printed G1/4 threads. Inputs in the channels with water were indented with a small space for the pressure sensor to have a small space between the main flow and the sensor itself. The detail of the prepared threads for sensor connection is shown in Fig. 4.

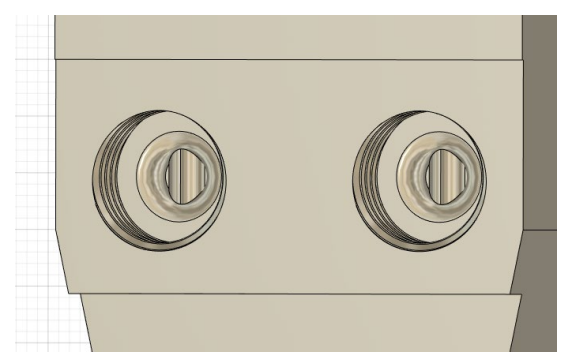

Figure 4. Pressure sensors location detail

Slicing was done with standard settings with the exception of perimeters. For better results in layer adhesion, we used 4 perimeters with $0,2 \mathrm{~mm}$ layer height (Fig. 5).

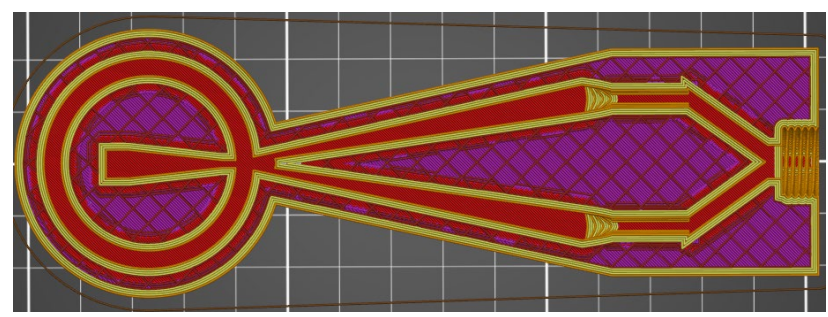

Figure 5. Midsection of sliced fluidic in PrusaSlicer (red: top layers, yellow: perimeters, purple: infill)

\section{CFD MODELLING}

In the present study, the flow was considered turbulent, incompressible due to the low static pressure and low compressibility of water and isothermal. All simulations were 3D and transient. The working fluid was water.

\subsection{Governing equations}

The main governing equations describing the flow in fluidic oscillator presented in this paper can be found in many CFD textbooks [Anderson 1995] or [Ferziger 1996]. The governing equations of mass and momentum conservation for incompressible and isothermal flow are defined as follows:

$$
\begin{aligned}
& \frac{\partial u_{j}}{\partial x_{j}}=0 \\
& \frac{\partial u_{i}}{\partial t}+u_{j} \frac{\partial\left(u_{i}\right)}{\partial x_{j}}=-\frac{1}{\rho} \frac{\partial p}{\partial x_{i}}+v \frac{\partial^{2} u_{i}}{\partial x_{j} \partial x_{j}}
\end{aligned}
$$

where $u, p, \rho, v$ are velocity, pressure, density, and kinematic viscosity of the fluid. As the flow was modelled as turbulent, this basic mathematical model was further extended with additional transport equations. The shear stress transport $k$ - $\omega$ model was chosen from the RANS family due to high shear stress, jet flow, and low Reynolds number in the fluidic oscillator. The governing equations were solved by the finite volume method employed in CFD software Ansys CFX.

\subsection{Computational grid}

The computational grid was created as pure hexahedral. The grid was generated as one half, then mirrored, and connected in CFD code. This procedure provided symmetric computational mesh necessary for modelling the periodic flow as shown in Fig. 6 . The final mesh with ca 5 million cells was used in CFD code after the independent test.

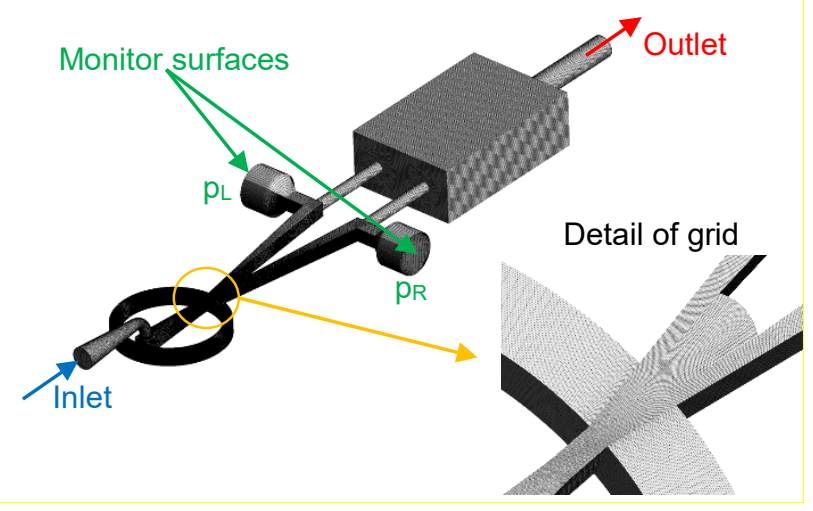

Figure 6. A general view of the final computational grid 


\subsection{Boundary conditions}

A uniform velocity was assumed at the inlet, corresponding to the flow rate and cross-sectional area of the inlet pipe. The fractional intensity of turbulence was estimated as $5 \%$ and hydraulic diameter was defined according to geometry as $8 \mathrm{~mm}$. Outlet boundary condition was specified as pressure outlet with relative pressure set to $\mathrm{OPa}$. Two surfaces were specified as monitor entity $P_{R}$ (pressure right) and $P_{L}$ (pressure left) as illustrated in Fig. 6. Both surfaces were used to evaluation of pressure fluctuation. A no-slip boundary condition was adopted at all walls.

\subsection{Solution parameters}

The coupled pressure-based solver was applied. The stability of the numerical solution was checked by the Courant number. This number evaluates the time step requirements of a numerically stable transient simulation [Ferziger 1996] and is defined according to eq. (3):

$$
C r=\frac{u \cdot \Delta t}{\Delta h}
$$

where $u$ is velocity, $\Delta t$ is the time step of the simulation, and $\Delta h$ is the characteristic size of the grid (size of elements). The convergence criterion for continuity and momentum equations was set to 1e-6. The Courant number monitored in CFD simulation was less than 1 , which represented time step in order millionth of a second.

\subsection{Simulation results}

The simulation was carried out for four values of volume flow rate defined in Tab. 1 . The Reynolds number based on the velocity and the hydraulic diameter at the nozzle throat (4) was used to characterize the main flow.

$$
\operatorname{Re}=\frac{u \cdot d_{h}}{v}
$$

In spite of the first value, the considered Reynolds numbers are within the turbulent flow regime.

\begin{tabular}{|l|l|l|l|l} 
CFD & $\begin{array}{l}\mathbf{Q} \\
{[\mathrm{I} / \mathrm{h}]}\end{array}$ & $\begin{array}{l}\mathbf{Q} \\
{[\mathrm{I} / \mathrm{s}]}\end{array}$ & $\begin{array}{l}\mathbf{R} \text { (nozzle) } \\
{[\mathrm{m} / \mathrm{s}]}\end{array}$ & $\begin{array}{l}\mathbf{R e} \\
{[1]}\end{array}$ \\
\hline $\mathbf{1}$ & 16 & 0,0044 & 0,889 & 1481 \\
\hline $\mathbf{2}$ & 32 & 0,0088 & 1,778 & 2963 \\
\hline $\mathbf{3}$ & 64 & 0,0177 & 3,556 & 5926 \\
\hline $\mathbf{4}$ & 128 & 0,0353 & 7,111 & 11852
\end{tabular}

Table 1. Definition of tested values

During the simulation, pressure oscillations were monitored for further post-processing. Fig. 7 shows the stable sinusoidal oscillation of monitored pressures $p_{\mathrm{L}}$ and $p_{\mathrm{R}}$ and velocity in the feedback loop. The performance of the fluidic oscillator was evaluated using three parameters: frequency of oscillation $f$, amplitude of pressure fluctuations $p_{\mathrm{A}}$, and the pressure drop $\Delta p$ through the fluidic oscillator. For each flowrate, the oscillation frequency was extracted from the calculated pressure oscillation via spectral analysis. The main results are presented in Tab. 2 .

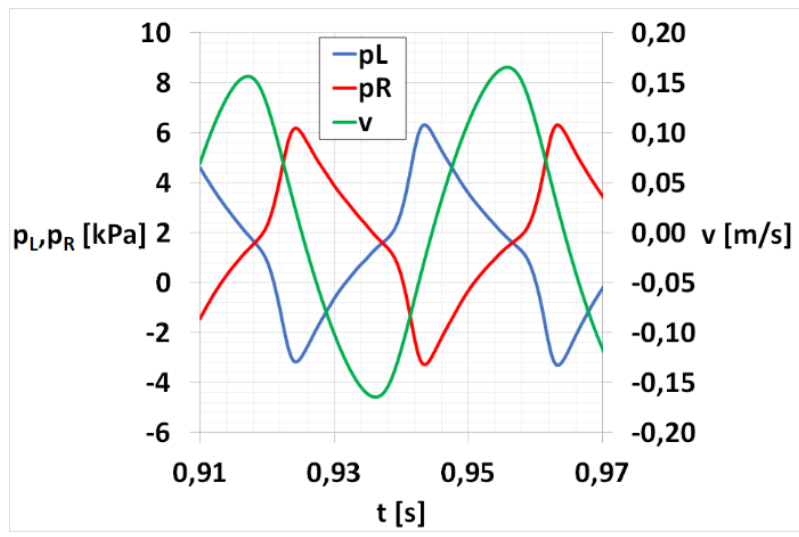

Figure 7. Time record of pressure fluctuations $p_{R}, p_{\mathrm{L}}$ and velocity in the feedback loop (CFD Q = $128 \mathrm{I} / \mathrm{h}, \mathrm{Re}=11852$ )

\begin{tabular}{|l|l|l|l|l|l|}
$\mathbf{C F D}$ & $\begin{array}{l}\mathbf{Q} \\
{[\mathrm{l} / \mathrm{h}]}\end{array}$ & $\begin{array}{l}\Delta \mathbf{p} \\
{[\mathrm{kPa}]}\end{array}$ & $\begin{array}{l}\mathrm{PA} \\
{[\mathrm{kPa}]}\end{array}$ & $\begin{array}{l}\mathbf{f} \\
{[\mathrm{Hz}]}\end{array}$ & {$[1]$} \\
\hline $\mathbf{1}$ & 16 & 0,7 & 0,1 & 2,47 & 0,0028 \\
\hline $\mathbf{2}$ & 32 & 2,6 & 0,3 & 5,51 & 0,0031 \\
\hline $\mathbf{3}$ & 64 & 9,5 & 1,3 & 12,35 & 0,0034 \\
\hline $\mathbf{4}$ & 128 & 35,6 & 4,4 & 24,51 & 0,0034 \\
\hline
\end{tabular}

Table 2. Main results of CFD simulations

Strouhal number (5) was evaluated based on calculated switching frequency, nozzle width, and the velocity of the jet emerging from the nozzle.

$S r=\frac{f \cdot d}{u}$

It can be seen that fluidic oscillator operates under nearly constant Strouhal number as the frequency response is proportional to the increase in velocity.

Fig. 8 shows numerical results for time-dependent contours of velocity for one oscillation cycle.

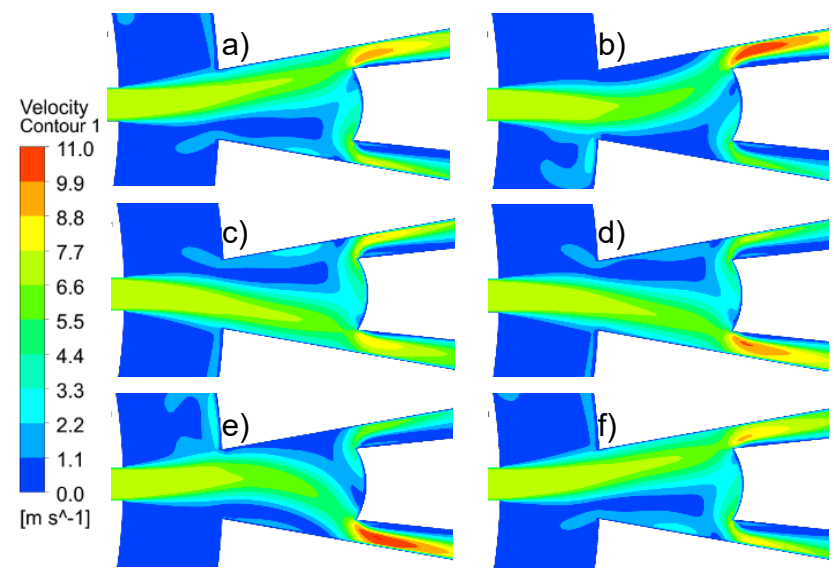

Figure 8. Velocity contours, jet oscillation per one oscillating period $\mathrm{T}=0,04 \mathrm{~s}$, (CFD Q = $128 \mathrm{I} / \mathrm{h}, \mathrm{Re}=11852$ )

The detail of velocity contours in the inlet part is presented in Fig. 9 for $\mathrm{Re}=11852$. Maximum velocity corresponds to the acceleration in the nozzle throat. 

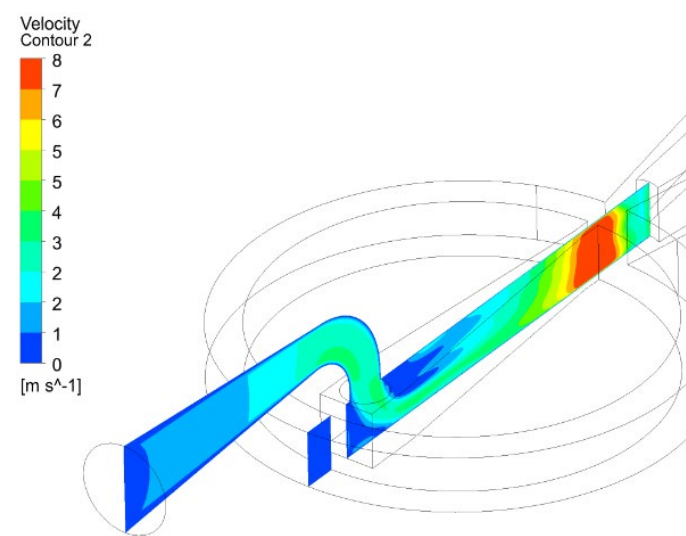

Figure 9. Velocity contours (CFD Q = $128 \mathrm{l} / \mathrm{h}, \mathrm{Re}=11852$ )

Another task was to define the volume flow rate in the feedback loop. Although the velocity in the feedback loop continually increases with increasing flow rate, the ratio of the incoming flowrate and the feedback channel flowrate decreases as depicted in Tab.3. This may be due to increasing friction losses in the narrow and long feedback channel.

\begin{tabular}{|l|l|l|l|l|l|}
$\mathbf{C F D}$ & $\begin{array}{l}\mathbf{Q} \\
{[\mathrm{I} / \mathrm{h}]}\end{array}$ & $\begin{array}{l}\mathbf{Q}_{\text {loop }} \\
{[\mathrm{l} / \mathrm{h}]}\end{array}$ & $\begin{array}{l}\mathbf{Q}_{\text {loop }} / \mathbf{Q} \\
{[\%]}\end{array}$ & $\begin{array}{l}\mathbf{R} e_{\text {jet }} \\
{[\mathbf{1}]}\end{array}$ & $\begin{array}{l}\mathbf{R e} \text { loop } \\
{[1]}\end{array}$ \\
\hline $\mathbf{1}$ & 16 & 0,84 & 5,3 & 1481 & 176 \\
\hline $\mathbf{2}$ & 32 & 1,56 & 4,9 & 2963 & 325 \\
\hline $\mathbf{3}$ & 64 & 2,97 & 4,6 & 5926 & 619 \\
\hline $\mathbf{4}$ & 128 & 5,61 & 4,4 & 11852 & 1168 \\
\hline
\end{tabular}

Table 3. Evaluation of the flow rate in the feedback loop

To confirm the validity of the results obtained with CFD simulation, a physical experiment was prepared.

\section{EXPERIMENTAL MEASUREMENT}

Fig. 10 schematically shows the experimental circuit.

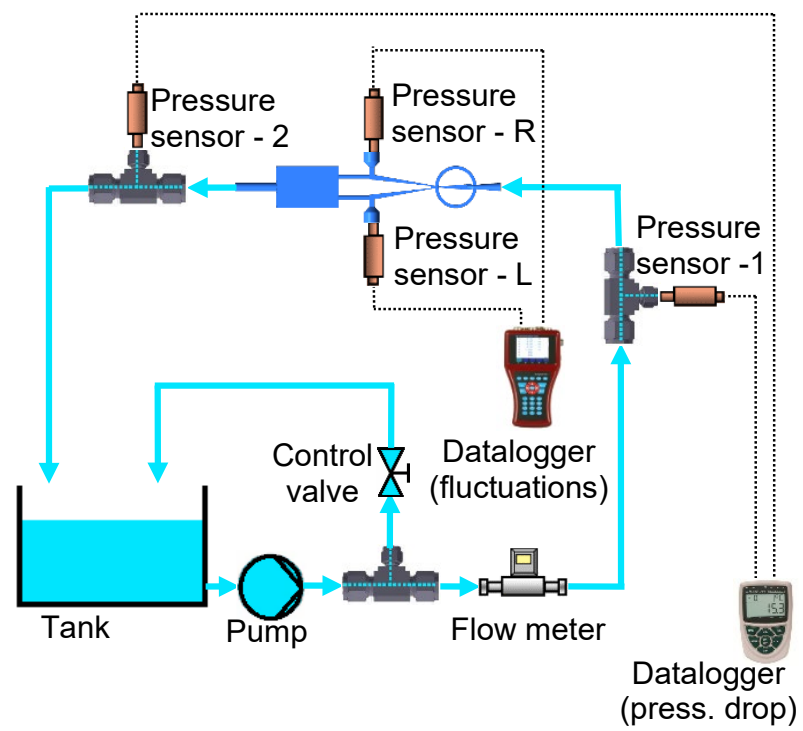

Figure 10. Set-up of experiment

The centrifugal pump Grundfos Magna 1 25-80 was used as a source of hydraulic energy. The flow of water through the fluidic oscillator was set by the manual by-pass control valve. The volume flow rate was measured using the induction flow meter Flomic FL 1014 (range 10-2500 l/h, accuracy $\pm 0.5 \%$ ). The piezoresistive pressure sensors FDAD 3302 with integrated $A / D$ converter and signal processor were placed at the inlet and outlet fitting of the fluidic to measure the pressure drop $\Delta \mathrm{p}$. The upstream sensor (FDAD 3302R, 0-3 bar, accuracy $\pm 0.5 \%$ ), and downstream sensor (FDAD 3302A, $-1-2$ bar, accuracy $\pm 0.5 \%$ ) were installed via T-junction and monitored by measuring instrument and data logger AHLBORN ALMEMO ${ }^{\circledR} 2590 \mathrm{~A}$. The applied instrumentation is shown in Fig. 11.

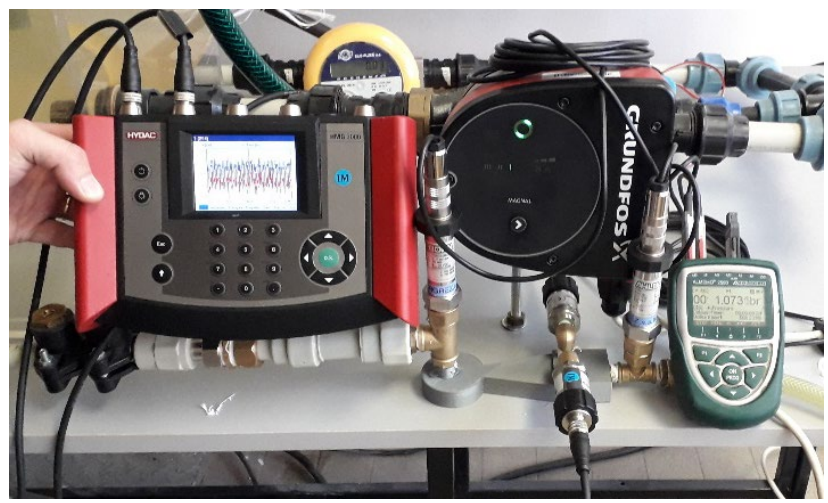

Figure 11. Experimental instrumentation

The pressure fluctuation in the left and right channels of the fluidic were measured using piezoelectric pressure transducers (Hydac's HDA 4346-A-000-F1, -1-5 bar, accuracy $\pm 0.5 \%$ ), with the electric output directly observed using portable data recorder Hydac HMG 3000, see Fig. 12.

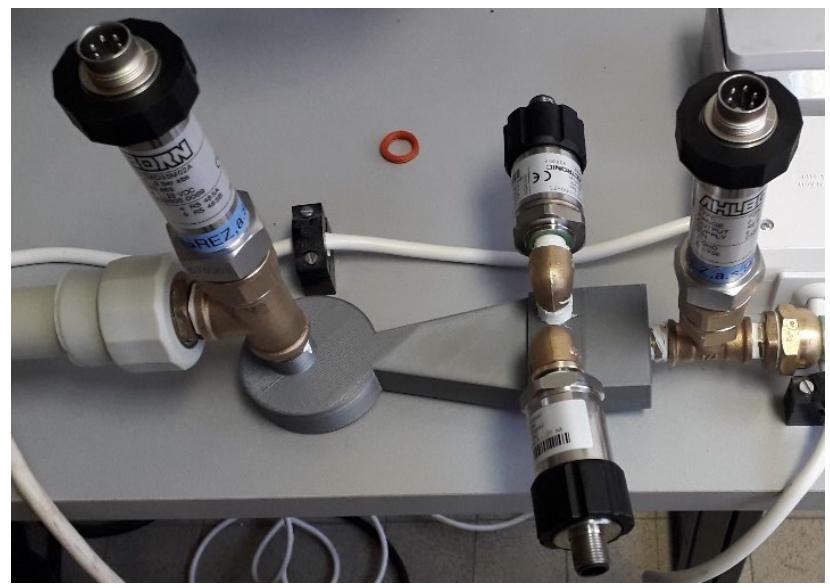

Figure 12. Pressure transducers installed on the fluidic oscillator.

Data were stored in the data logger with a sampling period $\Delta t=$ $0,3 \mathrm{~s}$. The ,left" and ,right" pressure were measured with sampling period $\Delta t=1 \mathrm{~ms}$. Type $A$ and Type $B$ uncertainty were evaluated for every measured variable in Tab. 4 . (4x pressure, $1 \mathrm{x}$ volume flow rate).

\begin{tabular}{|l|l|l|l|l|}
$\begin{array}{l}\text { Meas. } \\
\text { no. }\end{array}$ & $\begin{array}{l}\mathbf{Q} \\
{[\mathrm{l} / \mathrm{h}]}\end{array}$ & $\begin{array}{l}\Delta \mathbf{p} \\
{[\mathrm{kPa}]}\end{array}$ & $\begin{array}{l}\mathbf{p}_{A} \\
{[\mathrm{kPa}]}\end{array}$ & $\mathbf{f}$ \\
{$[\mathrm{Hz}]$}
\end{tabular}

Table 4. Main results of experimental measurement 
The DFT analysis of periodic pressure fluctuation was used for the estimation of frequency $f$ and amplitude $p_{\mathrm{A}}$ of a periodic signal. According to the Nyquist-Shannon sampling theorem, the maximum measurable frequency of fluctuations was ca $400 \mathrm{~Hz}$, which was sufficient in this case, as the expected frequency of fluctuation is $50 \mathrm{~Hz}$.

\section{COMPARISON OF RESULTS AND DISCUSSION}

Same as in CFD simulation, the performance of the fluidic oscillator was evaluated using the frequency of oscillation $f$, amplitude of pressure fluctuations $p_{\mathrm{A}}$, and the pressure drop $\Delta p$ through the fluidic oscillator. To analyze the frequency response, a discrete Fourier transform (DFT) on each recorded waveform from the pressure transducers was performed.

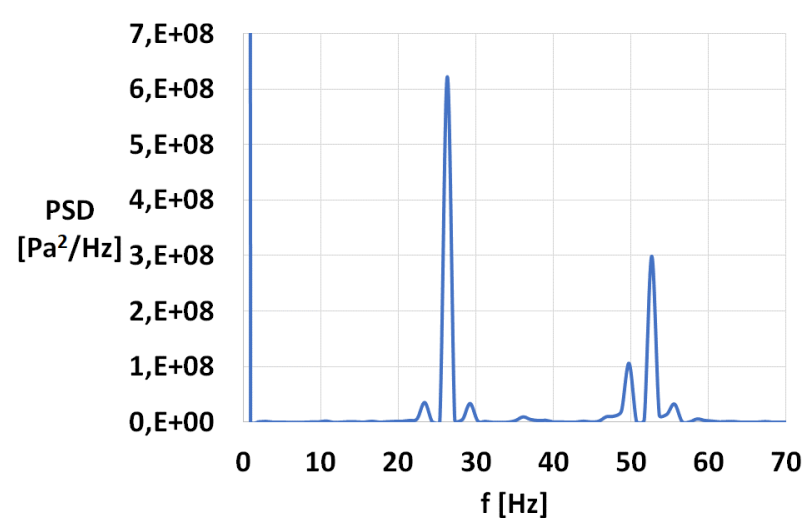

Figure 13. DFT analysis of pressure fluctuations (Meas., $Q=130 \mathrm{I} / \mathrm{h}$ )

Fig. 13 shows the first and second harmonic corresponding to stable sinusoidal oscillation. The data obtained from numerical simulation and measurement were further compared in the following Fig. 14, 15, 16. One of the main characteristics of a fluidic oscillator is linear frequency behavior versus the inlet flow rate. This comparison is presented in Fig. 14 and clarifies that the expected linear behavior appears both in numerical and experimental results.

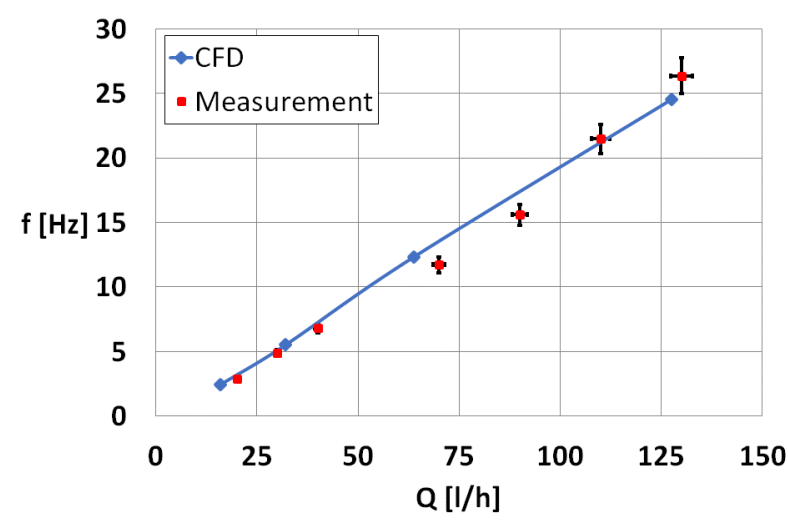

Figure 14. Frequency of pressure fluctuations

Fig. 15 shows the pressure drop between the inlet and outlet of the fluidic oscillator. Measurement shows higher values than predicted in the numerical simulation. This may be due to the additional losses in junctions, internal roughness in fluidic, etc. that cannot be included in the mathematical model. On the opposite, the pressure amplitude $\mathrm{p}_{\mathrm{A}}$ predicted with numerical simulation is higher in comparison with measurement (Fig. 16).

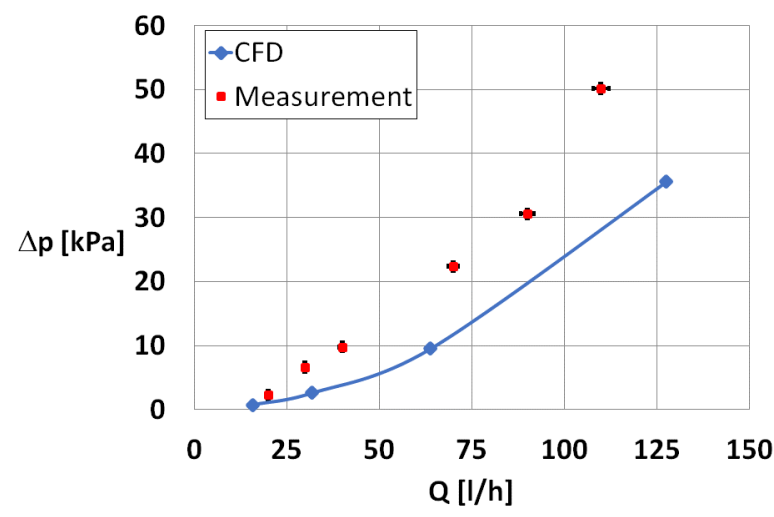

Figure 15. Pressure drop through the oscillator

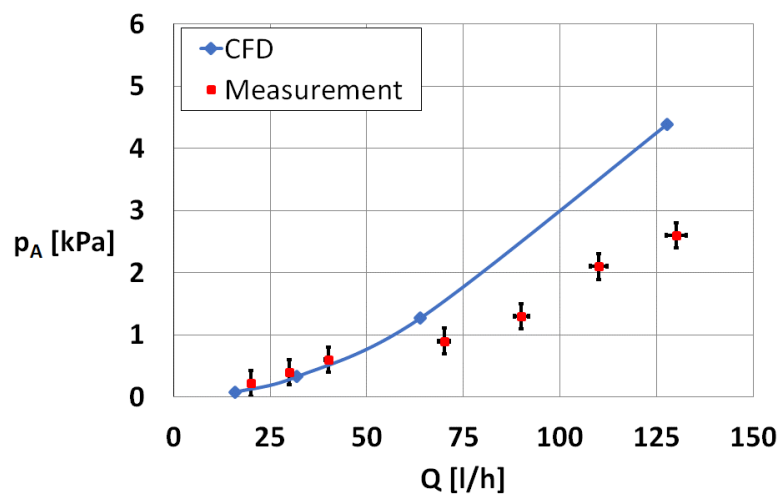

Figure 16. Amplitude of pressure fluctuations

Based on the data obtained by numerical modelling and measurement, an attempt has been done to evaluate the theoretically available power output for further transformation into electrical energy. The power loss $\mathrm{P}_{\text {lost }}$ in fluidic oscillator was evaluated based on the volume flow rate and pressure drop through the fluidic oscillator. Usable power Pu was estimated as time derivation of pressure energy of matter available in cylinder volume (cylindrical hole for installation of sensor $p_{\mathrm{L}}$ and $p_{\mathrm{R}}$ ). Effectivity of energy transformation harvested from the fluidic oscillator is represented as a ratio of usable power to power loss, this value is presented in \%.

Another possibility of power estimation is based on the deformation of the piezoelectric element. Piezoelectric energy harvester can produce an output voltage in response to mechanical input. The piezoelectric devices for harnessing energy from water oscillation in fluidic were assumed with the same geometry as the monitoring surfaces $p_{L}$ and $p_{R}$. The parameters of piezo material were chosen as follows: type AIN, thickness $t=0,2 \mathrm{~mm}$, piezo constant $d_{33}=3,9 \mathrm{pm} / \mathrm{V}$, elastic modulus $\mathrm{G}=308 \mathrm{GPa}$. Exploitable voltage is presented in Tab. 5 .

\begin{tabular}{|l|l|l|l|l|l|}
\hline $\begin{array}{l}\text { Meas. } \\
\text { no. }\end{array}$ & $\begin{array}{l}\mathbf{Q} \\
{[l / h]}\end{array}$ & $\begin{array}{l}\text { Plost } \\
{[\mathrm{W}]}\end{array}$ & $\begin{array}{l}\mathbf{P u}_{\mathrm{u}} \\
{[\mathrm{mW}]}\end{array}$ & $\begin{array}{l}\text { Effect. } \\
{[\%]}\end{array}$ & $\begin{array}{l}\mathbf{V}_{\text {piezo }} \\
{[\mathrm{V}]}\end{array}$ \\
\hline $\mathbf{1}$ & 20 & 0,013 & 0,783 & 6,2 & 0,024 \\
\hline $\mathbf{2}$ & 30 & 0,055 & 1,414 & 2,6 & 0,038 \\
\hline $\mathbf{3}$ & 40 & 0,109 & 2,122 & 2,0 & 0,057 \\
\hline $\mathbf{4}$ & 70 & 0,434 & 3,181 & 0,7 & 0,106 \\
\hline $\mathbf{5}$ & 90 & 0,763 & 4,595 & 0,6 & 0,163 \\
\hline $\mathbf{6}$ & 110 & 1,532 & 7,422 & 0,5 & 0,292 \\
\hline $\mathbf{7}$ & 130 & 2,563 & 9,769 & 0,4 & 0,410 \\
\hline
\end{tabular}

Table 5. Estimation of harvested power from the flow through fluidic oscillator 


\section{CONCLUSIONS}

Energy harvesting from water flow could be one of the alternative sources of energy to power electronic devices. A fluidic oscillator with no moving components shows potential for piezoelectric energy harvesting. The design of water-operated fluidic oscillators presented in [McDonough et al. 2017] has been investigated using CFD simulations and measurement on the 3D printed prototype. Unsteady RANS simulations of a fluidic oscillator were carried out and the performance was investigated in varying Reynolds numbers. The numerical results were compared with available physical experiment. The performance of the fluidic oscillator was evaluated using the frequency of oscillation $f$, the amplitude of pressure fluctuations $P_{A}$, and the pressure drop $\Delta p$ through the fluidic oscillator. A linear relationship between the frequency of oscillation and flow rate was reached both in numerical simulation and measurement. Frequencies of $2-27 \mathrm{~Hz}$ were produced for kinematic viscosities of $10^{-6} \mathrm{~m}^{2} / \mathrm{s}$, in the range of $\operatorname{Re}_{\text {NOZZLE }}=1500$ 12000. Pressure loss measured on the prototype was higher than that predicted by the numerical modelling. Exploitable power output for further transformation into electrical energy was estimated. There are many questions left in connection with this topic, so further investigation of piezoelectrics in energy harvesting from fluid oscillation is expected and recommended.

\section{ACKNOWLEDGMENTS}

This work has received funding from the European Union's Horizon 2020 research and innovation programme under grant agreement no. 856670; the developing was funded by the project CZ.01.1.02/0.0/0.0/15_019/0004955 “Energy Harvesting from environment free of Battery Supply to Measuring energy consumption in the SMART Grid Network" of the Operational Program of Business and Innovation for Competitiveness.

\section{REFERENCES}

[Anderson 1995] Anderson Jr., J.D. Computational Fluid Dynamics. The Basics with Applications, McGraw-Hill, USA, 1995. ISBN 0-07-001685-2

[Bobusch et al. 2013] Bobusch, B.C., et al. Experimental study of the internal flow structures inside a fluidic oscillator. Exp. Fluids 2013, 54, p. 1559.

\section{CONTACTS:}

doc. Ing. Tomas Blejchar, PhD. Faculty of Mechanical Engineering VSB-Technical University of Ostrava Department of Hydromechanics and Hydraulic Equipment 17. listopadu 2172/15, Ostrava, 70800, Czech Republic Email: tomas.blejchar@vsb.cz

URL: http://www.338.vsb.cz/

URL: http://homel.vsb.cz/ ble02/
[Cerretelli and Kirtley 2009] Cerretelli, C. and Kirtley, K. Boundary layer separation control with fluidic oscillators. J. Turbomach. 2009, 131, 041001.

[Ferziger and Peric 1996] Ferziger, J. H. and Peric, M.

Computational methods for fluid dynamics. Berlin: Springer, 1996. ISBN 3-540-59434-5

[Gregory and Tomac 2013] Gregory, J. W. and Tomac, M. N. A review of fluidic oscillator development and application for flow control, AIAA Paper, 2013, 2474.

[Guyot et al. 2008] Guyot, D., et al. Active combustion control using a fluidic oscillator for asymmetric fuel flow modulation. In Proceedings of the 44th AIAA/ASME/SAE/ASEE Joint Propulsion Conference \& Exhibit, Hartford, CT, USA, 21-23 July 2008; p. 4956

[Hamlehdar et al. 2019] Hamlehdar, M., et al. Energy harvesting from fluid flow using piezoelectrics: A critical review. Renewable Energy, Volume 143, December 2019, pp. 1826-1838

[Krüger et al. 2013] Krüger, O., et al. Numerical Modeling and Validation of the Flow in a Fluidic Oscillator. In Proceedings of the 21st AIAA Computational Fluid Dynamics Conference, San Diego, CA, USA, 24-27 June 2013; p. 3087.

[McDonough et al. 2017] McDonough, J.R., et al. Effect of geometrical parameters on flow-switching frequencies in 3D printed fluidic oscillators containing different liquids. J. chemical engineering research and design 117, 2017, pp. 228-239

[Pandey and Kim] Pandey, R.J. and Kim, K.Y. Numerical modeling of internal flow in a fluidic oscillator. J. Mech. Sci. Technol. 2018, 32, pp. 1041-1048.

[Raman and Raghu 2012] Raman, G. and Raghu, S. Cavity resonance suppression using miniature fluidic oscillators, AIAA Paper (2012) pp. 2608-2612.

[Tesař 2007] Tesař, V. Pressure Driven Microfluidic. Artech House Publishers, Norwood, USA. 2007. ISBN-10:1596931345

[Warren 1960] Warren, R. W. Fluid oscillator, US Patent 3,016,066, filed 22nd Jan 1960.

[Woszidlo et al. 2019] Woszidlo, R., et al. Fundamental properties of fluidic oscillators for flow control applications. AIAA J. 2019, 57, pp. 978-992. 